\title{
Episodic Neoglacial expansion and rapid 20th century retreat of a small ice cap on Baffin Island, Arctic Canada, and modeled temperature change
}

Simon L. Pendleton et al.

Correspondence to: Simon L. Pendleton (simon.pendleton@colorado.edu)

The copyright of individual parts of the supplement might differ from the CC BY 3.0 License. 
Supplemental Information

1. Alternative Time-Distance Plot

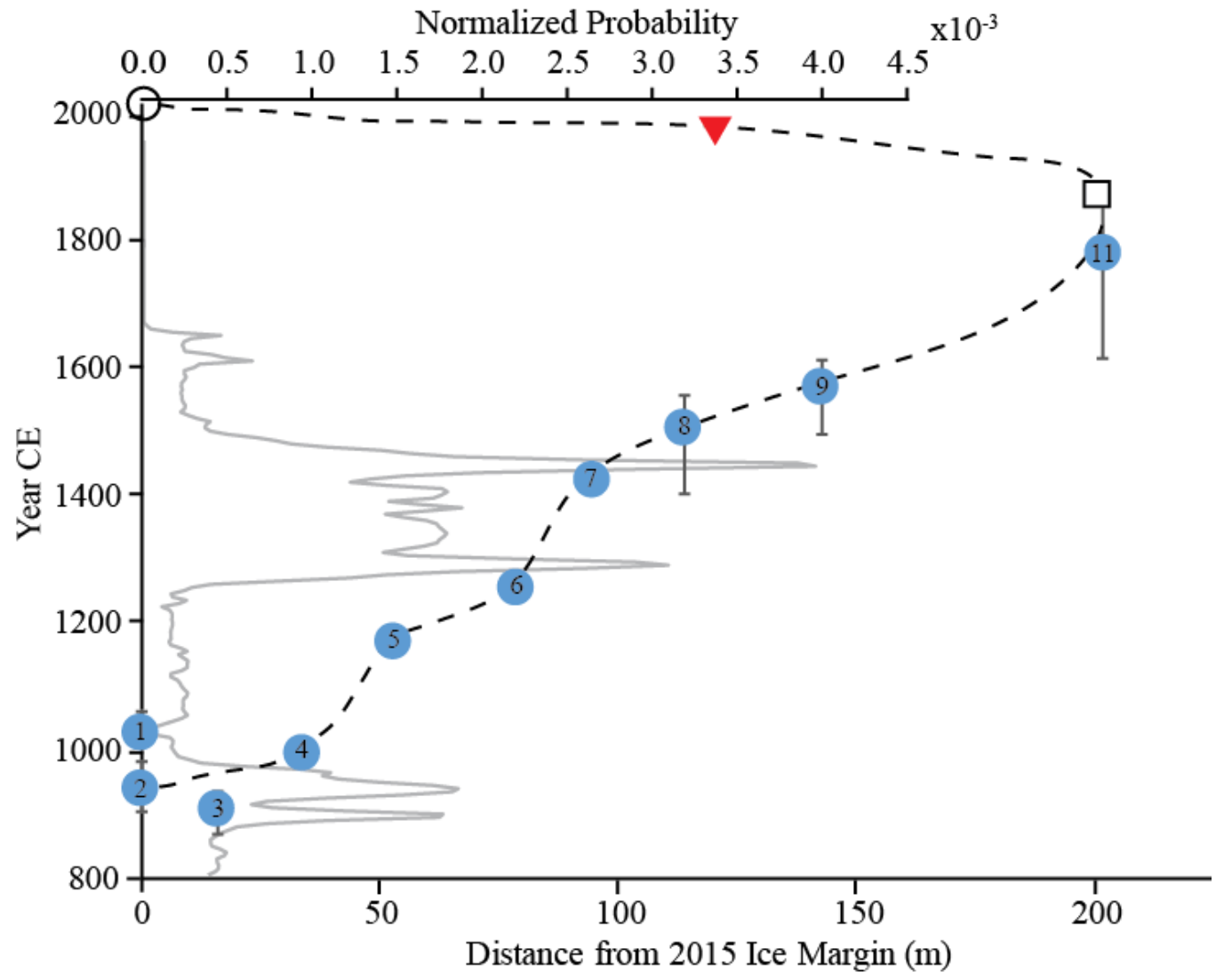

6
Figure S1: An alternative view of manuscript Figure 3. The same transect radiocarbon ages are show here in a Time vs. Distance away from 2015 Ice margin. All other aspects of the figure are the same as main manuscript Figure 3. 
2. Ice Margin In situ Plant ages (from manuscript Figure 3)

\begin{tabular}{|c|c|c|c|c|c|c|c|c|}
\hline Field ID & Latitude & Longitude & $\begin{array}{c}\text { Elevation } \\
\text { (m) }\end{array}$ & ${ }^{14} \mathrm{C}$ age (yr) & ${ }^{14} \mathrm{C} \pm(\mathrm{yr})$ & $\begin{array}{c}\text { Cal. BP } \\
\text { Age (1950)* }\end{array}$ & $\begin{array}{c}\text { Uncertaint } \\
\text { y (-yr) }\end{array}$ & $\begin{array}{c}\text { Uncertainty } \\
(+y r)\end{array}$ \\
\hline 09SRB-E265A-01 & 66.1052081 & -64.587198 & 1037 & 155 & 20 & 158 & -149 & 116 \\
\hline 09SRB-K047A-01 & 66.2154431 & -64.370017 & 959 & 165 & 25 & 160 & -154 & 121 \\
\hline 09SRB-K051A-01 & 66.2483348 & -64.272212 & 1045 & 185 & 20 & 167 & -167 & 116 \\
\hline 09SRB-K048A-01 & 66.2186164 & -64.357094 & 998 & 165 & 15 & 168 & -159 & 107 \\
\hline 09SRB-K064A-01 & 66.1067164 & -64.337882 & 956 & 200 & 20 & 170 & -170 & 118 \\
\hline M09-B107v & 71.04155 & -74.66817 & 852 & 1215 & 25 & 211 & -57 & 86 \\
\hline 09SRB-E263A-01 & 66.1152081 & -64.569872 & 939 & 245 & 30 & 256 & -103 & 52 \\
\hline 09SRB-E266A-01 & 66.0965965 & -64.589275 & 1014 & 255 & 25 & 287 & -130 & 22 \\
\hline 09SRB-E263A-01 & 66.1152081 & -64.569872 & 939 & 255 & 15 & 290 & 3 & 15 \\
\hline 05SRP-17 & 71.495039 & -77.478825 & 780 & 275 & 15 & 336 & -39 & 82 \\
\hline M10-B032V & 70.90233 & -73.25257 & 1118 & 310 & 20 & 381 & -73 & 47 \\
\hline 05SRP-59 & 71.49829 & -77.51784 & 738 & 315 & 15 & 382 & -71 & 45 \\
\hline M10-B204V & 72.96828 & -82.79733 & 872 & 345 & 20 & 395 & -75 & 66 \\
\hline 05TGR-19 & 71.40865 & -78.77593 & 663 & 355 & 20 & 403 & -73 & 72 \\
\hline 05SRP-57B & 71.5443 & -77.3263 & 900 & 360 & 15 & 411 & -78 & 64 \\
\hline 09SRB-K098A-01 & 66.1951148 & -64.203042 & 1199 & 365 & 20 & 415 & -82 & 68 \\
\hline 09SRB-Q013A-01 & 66.2899331 & -64.037932 & 1000 & 385 & 25 & 437 & -102 & 63 \\
\hline 05ORN-50 & 71.5246 & -77.96909 & 797 & 390 & 15 & 463 & 5 & 35 \\
\hline 09SRB-K073A-01 & 65.7925798 & -63.943137 & 877 & 405 & 25 & 465 & 2 & 40 \\
\hline 09SRB-E264A-01 & 66.1103081 & -64.581673 & 970 & 405 & 20 & 475 & 1 & 29 \\
\hline 09SRB-K094A-01 & 66.2106964 & -64.190795 & 1309 & 405 & 20 & 475 & 1 & 29 \\
\hline 05SRP-39 & 71.51572 & -77.44729 & 742 & 400 & 15 & 478 & 0 & 23 \\
\hline 05PL-02 & 71.60063 & -78.4621 & 767 & 410 & 15 & 489 & -4 & 14 \\
\hline M09-B120v & 71.07193 & -74.69194 & 778 & 410 & 15 & 489 & -4 & 14 \\
\hline 05ORN-57 & 71.51777 & -77.97078 & 804 & 435 & 15 & 503 & -4 & 6 \\
\hline 05ORN-17 & 71.56608 & -78.09187 & 815 & 440 & 15 & 505 & -4 & 6 \\
\hline 05SRP-57A & 71.54432 & -77.32632 & 900 & 445 & 20 & 506 & -5 & 8 \\
\hline M09-B089v & 71.01734 & -74.8122 & 727 & 450 & 20 & 508 & -6 & 7 \\
\hline 05SRP-27 & 71.50665 & -77.48801 & 748 & 450 & 15 & 509 & -6 & 4 \\
\hline 05SRP-47 & 71.51874 & -77.39766 & 867 & 450 & 15 & 509 & -6 & 4 \\
\hline M09-B090v & 71.01851 & -74.8172 & 727 & 460 & 15 & 512 & -6 & 4 \\
\hline M81-BM6b & 71.31811 & -78.71281 & 660 & 460 & 25 & 512 & -8 & 8 \\
\hline 05SRP-16B & 71.47535 & -77.51295 & 797 & 465 & 15 & 513 & -6 & 5 \\
\hline 05SRP-24 & 71.49965 & -77.44927 & 845 & 480 & 15 & 518 & -7 & 5 \\
\hline 05SRP-52A & 71.52339 & -77.3551 & 874 & 480 & 20 & 519 & -9 & 6 \\
\hline 05ORN-43 & 71.53951 & -77.97321 & 781 & 505 & 15 & 526 & -6 & 7 \\
\hline M10-B198V & 73.19093 & -82.32833 & 881 & 510 & 15 & 528 & -6 & 7 \\
\hline 05SRP-29 & 71.50941 & -77.50816 & 696 & 530 & 20 & 542 & -17 & 2 \\
\hline 05ORN-59 & 71.51777 & -77.97078 & 804 & 550 & 15 & 563 & -29 & 54 \\
\hline M09-B093v & 71.05914 & -74.72184 & 904 & 550 & 20 & 568 & -35 & 52 \\
\hline 05SRP-58 & 71.52009 & -77.398027 & 863 & 560 & 15 & 577 & -38 & 44 \\
\hline M09-B041V & 71.45258 & -77.47724 & 766 & 560 & 20 & 580 & -42 & 43 \\
\hline 05SRP-56 & 71.53867 & -77.323176 & 885 & 565 & 15 & 583 & -42 & 39 \\
\hline $\mathrm{M} 09-\mathrm{B} 227 \mathrm{v}$ & 71.79554 & -76.60952 & 1066 & 565 & 15 & 583 & -42 & 39 \\
\hline
\end{tabular}

*Radiocarbon dates were calibrated using OxCal 4.2.4 (Bronk-Ramsey, 2009; Reimer et al., 2013) 
2.1. In situ Plant Ages (cont.)

\begin{tabular}{|c|c|c|c|c|c|c|c|c|}
\hline Field ID & Latitude & Longitude & $\begin{array}{l}\text { Elevation } \\
\text { (m) }\end{array}$ & ${ }^{14} \mathrm{C}$ age (yr) & ${ }^{14} \mathrm{C} \pm(\mathrm{yr})$ & $\begin{array}{c}\text { Cal. BP } \\
\text { Age (1950)* }\end{array}$ & $\begin{array}{c}\text { Uncertaint } \\
\text { y (-yr) }\end{array}$ & $\begin{array}{c}\text { Uncertainty } \\
(+\mathbf{y r})\end{array}$ \\
\hline $05 \mathrm{ORN}-54$ & 71.51621 & -77.95787 & 782 & 575 & 15 & 592 & -47 & 33 \\
\hline 05SRP-26 & 71.50126 & -77.45674 & 833 & 575 & 15 & 592 & -47 & 33 \\
\hline 05TGR-26 & 71.4064 & -78.82849 & 738 & 585 & 20 & 597 & -48 & 34 \\
\hline 05SRP-52B & 71.52339 & -77.3551 & 874 & 590 & 15 & 599 & -47 & 32 \\
\hline M10-B210V & 72.2462 & -79.12092 & 840 & 590 & 15 & 599 & -47 & 32 \\
\hline 05SRP-54 & 71.53457 & -77.33562 & 880 & 595 & 15 & 601 & -48 & 34 \\
\hline 05ORN-56B & 71.51511 & -77.96629 & 793 & 600 & 15 & 602 & -48 & 36 \\
\hline 05TGR-01 & 71.31821 & -78.70509 & 629 & 600 & 15 & 602 & -48 & 36 \\
\hline 05ORN-20 & 71.5614 & -78.06895 & 763 & 605 & 15 & 603 & -47 & 39 \\
\hline 05ORN-44 & 71.53889 & -77.97203 & 778 & 605 & 15 & 603 & -47 & 39 \\
\hline 05SRP-61 & 71.49398 & -77.54775 & 750 & 610 & 15 & 604 & -47 & 40 \\
\hline M09-B142v & 70.90735 & -73.61873 & 998 & 610 & 15 & 604 & -47 & 40 \\
\hline 05PL-04 & 71.60063 & -78.4621 & 767 & 615 & 15 & 604 & -46 & 42 \\
\hline 05SRP-66 & 71.48789 & -77.5524 & 774 & 615 & 15 & 604 & -46 & 42 \\
\hline 05TGR-09 & 71.377568 & -78.761183 & 746 & 620 & 15 & 605 & -46 & 43 \\
\hline $05 \mathrm{ORN}-62$ & 71.52676 & -77.994947 & 818 & 625 & 15 & 605 & -44 & 45 \\
\hline 09SRB-K092A-01 & 66.2037314 & -64.178252 & 1153 & 625 & 15 & 605 & -44 & 45 \\
\hline 05TGR-27 & 71.40521 & -78.82803 & 737 & 645 & 20 & 608 & -43 & 49 \\
\hline M09-B125v & 71.0746 & -74.67576 & 680 & 645 & 20 & 608 & -43 & 49 \\
\hline M09-B104v & 71.06007 & -74.71937 & 917 & 655 & 15 & 611 & -43 & 49 \\
\hline 05ORN-61 & 71.52076 & -77.98561 & 799 & 660 & 15 & 615 & -46 & 46 \\
\hline M09-B016V & 71.51554 & -76.53301 & 874 & 665 & 20 & 619 & -50 & 45 \\
\hline M09-B108v & 71.04024 & -74.65705 & 829 & 665 & 20 & 619 & -50 & 45 \\
\hline 05ORN-39 & 71.54166 & -78.00658 & 868 & 680 & 25 & 631 & -60 & 39 \\
\hline M10-B024V & 70.84775 & -73.4823 & 1007 & 675 & 15 & 634 & -60 & 33 \\
\hline M09-B099v & 71.062 & -74.71164 & 929 & 680 & 20 & 635 & -62 & 34 \\
\hline M09-B059V & 70.97187 & -74.7337 & 696 & 685 & 20 & 642 & -67 & 29 \\
\hline M09-B100v & 71.06192 & -74.71189 & 928 & 690 & 20 & 648 & 7 & 24 \\
\hline $05 \mathrm{ORN}-13$ & 71.58298 & -78.16529 & 829 & 685 & 15 & 649 & 7 & 20 \\
\hline 05TGR-13 & 71.38353 & -78.74943 & 708 & 690 & 15 & 655 & 3 & 14 \\
\hline 09SRB-K059A-01 & 66.1126931 & -64.265394 & 1025 & 715 & 20 & 669 & -4 & 8 \\
\hline M09-B127v & 71.07698 & -74.67796 & 661 & 715 & 15 & 670 & -4 & 5 \\
\hline 05ORN-38 & 71.54292 & -78.02479 & 892 & 725 & 15 & 674 & -5 & 4 \\
\hline 09SRB-K074A-01 & 65.7961098 & -63.944114 & 924 & 750 & 20 & 684 & -11 & 4 \\
\hline M10-B193V & 73.2208 & -81.98243 & 813 & 755 & 20 & 686 & -12 & 4 \\
\hline M09-B140v & 70.98071 & -73.66206 & 1143 & 765 & 15 & 690 & -13 & 3 \\
\hline 05ORN-23 & 71.5544 & -78.06365 & 790 & 780 & 15 & 700 & -18 & 22 \\
\hline 09SRB-K058A-01 & 66.1088498 & -64.260797 & 1066 & 845 & 20 & 751 & -20 & 29 \\
\hline 05ORN-09 & 71.58835 & -78.1943 & 825 & 880 & 25 & 800 & -60 & 91 \\
\hline M09-B141v & 70.98064 & -73.66207 & 1144 & 915 & 15 & 852 & -59 & 50 \\
\hline 05ORN-34 & 71.54297 & -78.02676 & 894 & 930 & 20 & 853 & -55 & 55 \\
\hline M10-B167V & 72.25617 & -77.29832 & 1145 & 930 & 20 & 853 & -55 & 55 \\
\hline 05ORN-10 & 71.58835 & -78.1943 & 825 & 940 & 15 & 853 & -53 & 59 \\
\hline M10-B174V & 72.24443 & -78.14567 & 1052 & 1050 & 20 & 954 & -19 & 7 \\
\hline
\end{tabular}

*Radiocarbon dates were calibrated using OxCal 4.2.4 (Bronk-Ramsey, 2009; Reimer et al., 2013)

15 
Holding all other parameters constant, the model was calibrated for a range of $m R$ values using the observed transect chronology. Given the asymmetry of the Holocene maximum extent (LIA) trimlines, there should be a small range of $m R$ values that can reproduce the observed ice cap dimensions (Fig. S2).
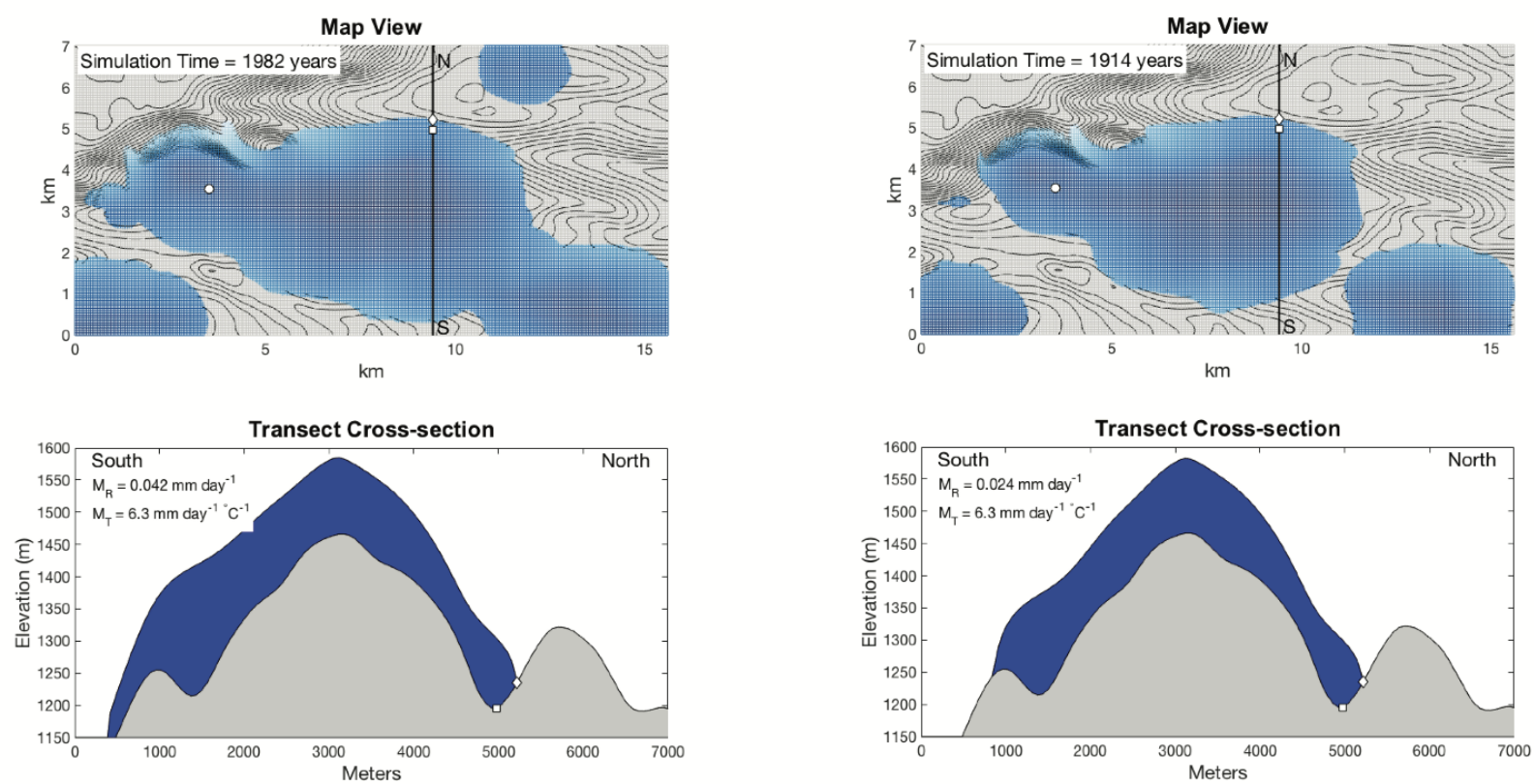

Figure S2: Results of the solar radiation melt factor calibration showing that, with all other parameters held constant, $m R$ values above and below $0.036 \mathrm{~mm}^{-1 a y}{ }^{-1}$ produce too much (left panel) or too little (right panel) ice, respectively, over the course of the simulation.

\section{Glacier Model Sensitivity Analysis}

Among the parameter values prescribed for this model, the uniform and constant accumulation rate is perhaps the most uncertain and therefore could have the largest impact on the model outcome. To test model sensitivity to accumulation rate, we ran the model to completion as above using 0.2 and 0.5 m.w.e. (meters water equivalent). Keeping all other parameters the same, including the solar radiation melt factor calibrated form the original run, simulations with $0.5 \mathrm{~m}$.w.e. fail to reproduce the correct LIA ice configuration. This is partly due to the fact that a higher accumulation rate has a higher equilibrium line altitude (ELA) and necessitates a warmer mean annual temperature than the original scenario to accumulate snow/ice at the same elevations (the same temperature forcing with a higher accumulation rate would produce too much ice and covers the entire study area). This higher temperature increases the length of the melt season (Fig. S3), therefore amplifying the influence of the solar radiation melt factor (which is only in effect when air temperature is above $0^{\circ} \mathrm{C}$ ). 


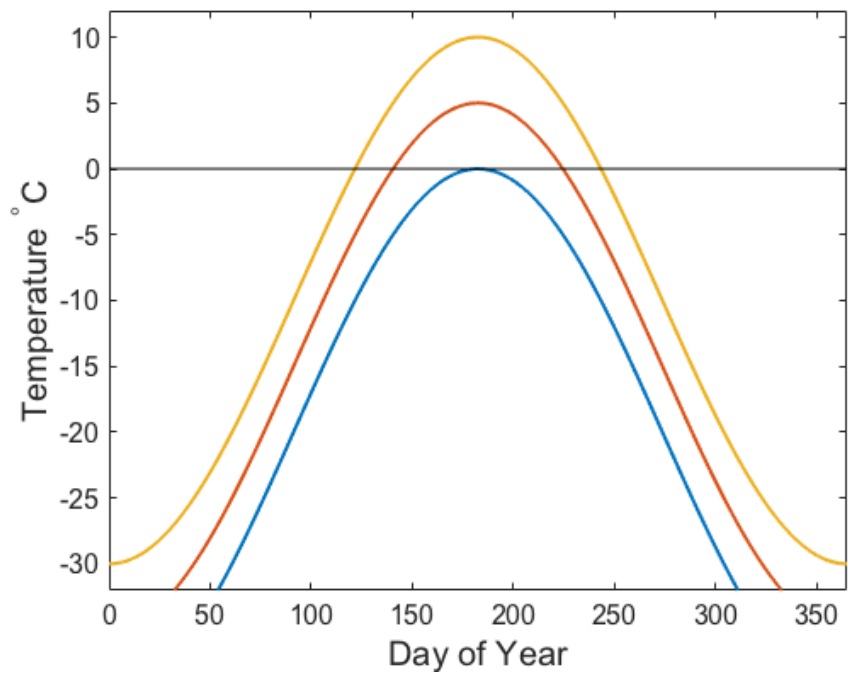

Supplemental Figure S3: Modeled daily annual temperatures illustrating the changing length of melt season (portion of curve above $0^{\circ} \mathrm{C}$ ) with changing mean annual temperature.

This then amplifies the asymmetry of ice distribution and prevents ice from advancing through the transect chronology as observed. However, when the solar melt factor is lowered to compensate for the above increase in melt season length, the only way to advance ice through the chronology in the observed time constraints is to raise temperatures during the $2^{\text {nd }}$ millennium CE and through the LIA, which itself it highly unlikely. Additionally, the Holocene maximum extent from these higher accumulation and lower solar melt factor runs deviate greatly from the observed maximum extent (Fig. S4).

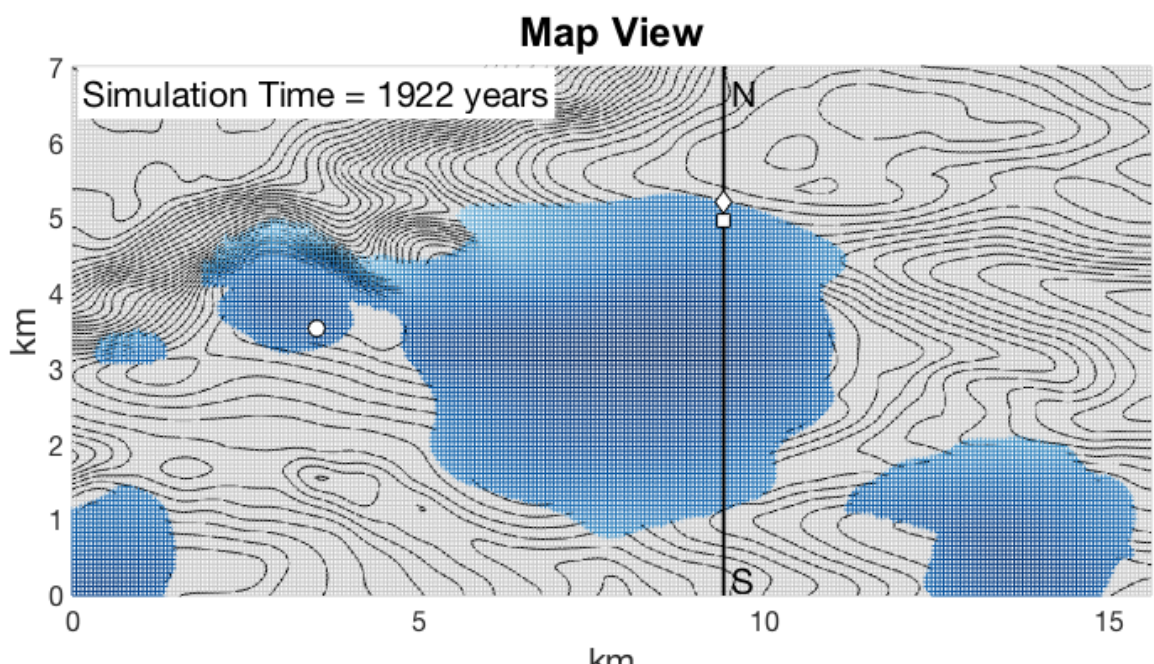

Supplemental Figure S4: Maximum Holocene extent under higher accumulation rate and lower solar radiation melt factor illustrating highly asymmetric configuration deviating from observed maximum extent (manuscript Figure 2). Also show are the locations of sample \#12 (circle), 1000CE margin (square), and LIA limit (diamond).

These results from the higher accumulation scenario suggest that indeed the accumulation rate at the study site is likely less than $0.5 \mathrm{~m}$.w.e.

Conversely, a lower accumulation rate of 0.2 m.w.e. raises the ELA and thus requires slightly cooler temperatures to accumulate ice at the correct elevations. When run with the 
same parameter values as the original simulation we find that total minimum required cooling over the last $\sim 2000$ years increases from 0.45 to $0.5^{\circ} \mathrm{C}$. This makes sense, since less accumulation would raise the ELA, then a temperature decrease is needed to lower it again. However, since cooler mean annual temperatures shorten the melt season, and lessening the influence of solar melt, model simulations with a lower accumulation rate have less asymmetry in the final ice configuration, and thus deviating from the observed Holocene maximum ice configuration (Fig. S5).

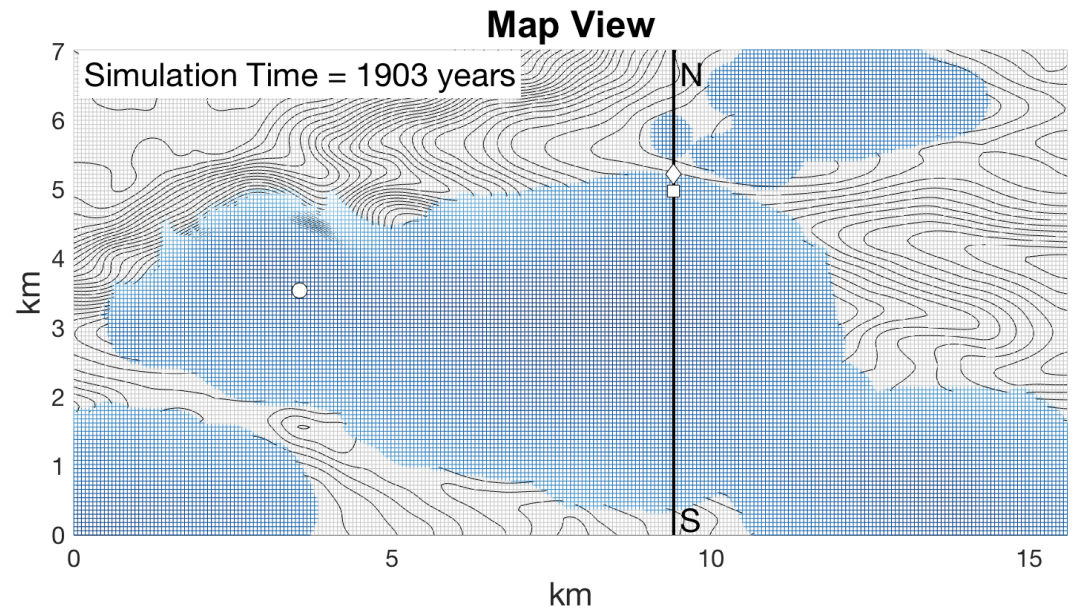

Figure S5: Modeled Holocene maximum extent using a lower accumulation and same solar radiation melt factor as LIA simulation in manuscript (Figure 4). Note lack of ice cap asymmetry which fails to match the observed maximum extent.

\section{Glacier Model Uncertainty}

In the modeling experiments used in this study, uncertainty is difficult to quantify, but it is worthwhile to acknowledge potential sources of error and uncertainty. First, though modeled ice thicknesses agreed with the thickness of modern ice removed to create an unglaciated surface, collection of subglacial topography data would greatly reduce the error here.

Second, sensitivity analysis showed that the accumulation rate is likely fairly accurate, however, longer term records of accumulation in the region would help to reduce uncertainty with the mass balance. Additionally, in situ mass balance data, including incoming solar radiation would allow for the calibration of a local solar radiation melt factor (e.g., Jonsell et al., 2012).

Third, super imposed ice (or refrozen melt water) is thought to be an important component of mass balance, especially for polar glaciers. However, even though refrozen melt water can account for up to $20 \%$ of annual accumulation (Wadham and Nuttall, 2002), it can vary significantly due to percolation and drainage flow paths (Cuffey and Paterson, 2010). (Zwinger and Moore, 2009) used in situ observation data to attempt to capture the effect of refreeze both in terms of accumulation and heat transfer. However, lacking any such data for DIC, attempting to model such a process would only introduce additional assumptions and uncertainty. Field observations of the ice cap showed numerous supraglacial 
88 meltwater channels and no obvious signs of large scale refreeze, suggesting that DIC may

89 shed meltwater efficiently, reducing the impact of super imposed ice.

$90 \quad$ Additionally, wind redistribution of snow likely plays a part in the mass balance of

91 Divide Ice cap and the asymmetry present in the Holocene maximum extent. Capturing this

92 factor is beyond the scope of this study, but important to acknowledge. The model in this

93 study captures the first-order trends and highlights areas of where similar future studies could

94 benefit from additional observation and measurements to reduce error and improve model

95 performance.

96

97

98 
99

100

101

102

103

104

105

106

107

108

109

110

111

112

113

114

115

116

117

\section{References}

Cuffey, K. M. and Paterson, W. S. B.: The physics of glaciers, Fourth ed., Academic Press, Kidlington, UK., 2010.

Jonsell, U., Navarro Valero, F. J., Bañón, M., Izargain, L., Jesús, J. and Otero García, J.: Sensitivity of a distributed temperature-radiation index melt model based on AWS observations and surface energy balance fluxes, Hurd Peninsula glaciers, Livingston Island, Antarctica, Cryosph., 6(3), 539-552, 2012.

Margreth, A., Dyke, A. S., Gosse, J. C. and Telka, A. M.: Neoglacial ice expansion and late Holocene cold-based ice cap dynamics on Cumberland Peninsula, Baffin Island, Arctic Canada, Quaternary Sci. Rev., 91, 242-256, doi:10.1016/j.quascirev.2014.02.005, 2014. Miller, G. H., Lehman, S. J., Refsnider, K. A., Southon, J. R. and Zhong, Y.: Unprecedented recent summer warmth in Arctic Canada, Geophys. Res. Lett., 40(21), 5745-5751, 2013.

Wadham, J. L. and Nuttall, A. M.: Multiphase formation of superimposed ice during a massbalance year at a maritime high-Arctic glacier, J. Glaciol., 48(163), 545-551, doi:10.3189/172756502781831025, 2002.

Zwinger, T. and Moore, J. C.: Diagnostic and prognostic simulations with a full Stokes model accounting for superimposed ice of Midtre Lovénbreen, Svalbard, Cryosph., 3, 217-229, doi:10.5194/tc-3-217-2009, 2009. 